\title{
EFEITO DA PRECIPITAÇÃO PELO ÁCIDO TRICLOROACÉTICO (TCA) E DA ULTRAFILTRAÇÃO SOBRE O PERFIL PEPTÍDICO DE HIDROLISADOS DE CASEÍNA
}

\author{
RAQUEL LINHARES CARREIRA ${ }^{1}$ \\ CLÉIA BATISTA DIAS ORNELLAS ${ }^{2}$ \\ HARRIMAN ALEY MORAIS ${ }^{2}$ \\ SILVANA DA MOTTA ${ }^{2}$ \\ MARIALICE PINTO COELHO SILVESTRE ${ }^{2}$
}

\begin{abstract}
RESUMO - Neste trabalho, estudou-se a influência da ultrafiltração e da precipitação pelo ácido tricloroacético (TCA) sobre o perfil peptídico de hidrolisados de caseína. Após esses tratamentos, os hidrolisados foram fracionados pela CLAE-EM (cromatografia líquida de alta eficiência - exclusão molecular), seguida da quantificação dos peptídeos nas frações cromatográficas pelo mé-
\end{abstract}

todo rápido da Área Corrigida da Fração (ACF). Observou-se que esses tratamentos alteraram o perfil peptídico, tendo reduzido os teores de di- e tripeptídeos da maioria das preparações enzimáticas. Algumas considerações relacionadas às condições operacionais e à influência da hidrofobicidade dos peptídeos foram feitas, no intuito de explicar os resultados obtidos.

TERMOS PARA INDEXAÇÃO: Hidrolisados de caseína, TCA, ultrafiltração, peptídeos.

\section{INFLUENCE OF PRECIPITATION AND ULTRAFILTRATION ON THE PEPTIDE PROFILE OF CASEIN HYDROLYSATES}

\begin{abstract}
The effect of ultrafiltration and precipitation by TCA on the peptide profile of casein hydrolysates was studied. After these treatments, the hydrolysates were fractionated by size-exclusion HPLC and the rapid Correct Fraction Area method was used for quantifying the peptides. These
\end{abstract}

INDEX TERMS: Casein hydrolysates, TCA, ultrafiltration, peptides.

\section{INTRODUÇÃO}

Os problemas nutricionais dos idosos, como a digestão e a absorção ineficientes das proteínas, vêm recebendo cada vez mais atenção por parte dos pesquisadores. O emprego de hidrolisados protéicos nesse grupo e também na dieta de indivíduos com intolerância protéica ou deficiência enzimática tem sido considerado após a comprovação de que preparações contendo di- e tripeptídeos, provenientes da hidrólise parcial de proteínas, são absorvidas mais eficientemente do que uma mistura equivalente treatments changed the peptide profile having reduced the di- and tripeptide content of some enzymatic preparations. In order to explain these results, some considerations concerning operational conditions and peptide hydrophobicity were made.

\footnotetext{
1. Autora da dissertação de Mestrado da qual este artigo faz parte.

2. Departamento de Alimentos, Faculdade de Farmácia, Universidade Federal de Minas Gerais, Av. Olegário Maciel, 2360 - 30180-112 - Belo Horizonte, MG, malice@farmacia.ufmg.br
} 
Nesse sentido, várias técnicas têm sido aplicadas para promover o enriquecimento dos hidrolisados em di- e tripeptídeos. Uma delas consiste no uso de agentes precipitantes, como o ácido tricloroacético (TCA), que permite a eliminação, total ou parcial, de proteínas e peptídeos de elevado peso molecular presentes nos hidrolisados (Aristoy \& Toldrá., 1991), e a taxa de precipitação depende do tipo de proteína e precipitante, bem como de suas respectivas concentrações (Greenberg \& Shipe, 1979; Yvon et al., 1989). Uma outra metodologia emprega membranas de ultrafiltração, com poros de dimensões variadas, que possibilitam a separação de peptídeos de acordo com o tamanho da cadeia (Deeslie \& Cheryan, 1988; Cheryan \& Mehaia, 1990; Cheryan, 1998), assim como a recuperação de produtos de baixo peso molecular (Lacroix et al., 1983).

Sendo assim, com este trabalho objetivou-se verificar o efeito da precipitação pelo TCA e o emprego da ultrafiltração sobre o perfil peptídico de hidrolisados de caseína. Após esses tratamentos, os hidrolisados foram fracionados por CLAE de exclusão molecular e, para a quantificação dos peptídeos, empregou-se o método rápido da Área Corrigida da Fração (ACF), desenvolvido anteriormente por Silvestre et al. (1994 a, b).

\section{MATERIAL E MÉTODOS}

\section{Material}

O sistema de CLAE consistiu de uma bomba isocrática (série HP1100), um detector espectrofotométrico em UV-VIS acoplado a um computador com software HPchemstation (HP1100, Germany) com a coluna cromatográfica PHEA [poli-(2-hidroxietilaspartamida)- sílica] $250 \times$ 9,4 mm, tamanho da partícula de $5 \mu \mathrm{m}$ e do poro de $200 \AA$ (PolylC, Columbia, MD). Foram utilizados liofilizador (Freezone (B) 45, Labconco, EUA), centrífuga refrigerada de bancada (Jouan BR4, EUA) e concentrador de amostras Centrivap (Labconco, EUA).

As enzimas tripsina de pâncreas bovino [tipo XIII, tratada com N-tosil-L-fenilalanina clorometilcetona (TPCK)], pepsina suína (P6887), subtilisina (carlsberg P-5380, tipoVIII do Bacillus licheniformis) e a caseína bovina (C7078) foram adquiridas da Sigma (St.Louis, MO). O ácido clorídrico e o ácido fórmico foram obtidos da Merck (Darmstadt, Germany) e o ácido tricloroacético (TCA), da Vetec (Duque de Caxias, RJ). Utilizou-se o sistema de ultrafiltração com corte de 5,000Da, UFV4BCC25 (Millipore, EUA). A água para uso no cromatógrafo foi purificada mediante da passagem pelo Sistema de Purificação de Água Aries (Vaponics, EUA). Todos os solventes usados no cromatógrafo foram cuidadosamente desgaseificados no banho de ultra-som, antes do uso.

\section{Métodos}

\section{Escolha das amostras}

Para este trabalho, foram utilizados os hidrolisados de caseína que apresentaram o melhor perfil peptídico para dietas especiais em trabalhos anteriormente realizados (Morato et al., 2000; Carreira et al., 2001) e que aqui foram denominados de $\mathrm{H} 1, \mathrm{H} 2$ e H3. As condições empregadas para o preparo desses hidrolisados estão apresentadas na Tabela 1.

TABELA 1 - Parâmetros hidrolíticos empregados no preparo dos hidrolisados de caseína.

\begin{tabular}{|c|c|c|c|c|}
\hline Hidrolisados & Enzimas presentes & Temperatura $\left({ }^{\circ} \mathrm{C}\right)$ & pH & $\mathrm{E}: \mathrm{S}(\%)$ \\
\hline $\mathrm{H} 1$ & Subtilisina (S) & 40 & 7,5 & $\mathrm{~S}=4,0$ \\
\hline \multirow{2}{*}{$\mathrm{H} 2$} & \multirow{2}{*}{ Tripsina $(\mathrm{T})+$ Pepsina $(\mathrm{P})$} & \multirow{2}{*}{37} & 7,5 & $\mathrm{~T}=3,3$ \\
\hline & & & 1,9 & $\mathrm{P}=4,0$ \\
\hline \multirow{3}{*}{ H3 } & \multirow{3}{*}{ Subtilisina $(\mathrm{S})+$ Tripsina $(\mathrm{T})+$ Pepsina $(\mathrm{P})$} & \multirow{3}{*}{37} & \multirow{3}{*}{$\begin{array}{l}7,5 \\
1,9\end{array}$} & $\mathrm{~S}=4,0$ \\
\hline & & & & $\mathrm{T}=3,3$ \\
\hline & & & & $\mathrm{P}=4,0$ \\
\hline
\end{tabular}

\section{E:S: relação enzima:substrato}




\section{Fracionamento dos hidrolisados de caseína}

O fracionamento dos hidrolisados foi realizado por CLAE-EM em coluna PHEA, como descrito por Silvestre et al. (1994b). As amostras foram dissolvidas em uma concentração de $1 \%$ em solução de ácido fórmico $\left(0,05\right.$ molesL $\left.^{-1}\right)$ e cromatografadas à temperatura ambiente, sob condições isocráticas, a um fluxo de $0,5 \mathrm{mLmin}^{-1}$, durante $35 \mathrm{~min}$. A fase móvel foi filtrada através de membrana de $0,45 \mu \mathrm{m}$, e sonicada imediatamente antes do uso. A detecção dos picos cromatográficos foi efetuada em três comprimentos de onda: 230, 280 e $300 \mathrm{~nm}$. As amostras foram analisadas em triplicatas, e as frações foram separadas de acordo com o tempo de retenção, sendo: F1, de 13,7 a 18,2 min; F2, de 18,2 a $21,7 \mathrm{~min}$; F3, de 21,7 a $22,7 \mathrm{~min}$; e F4, de 22,7 a 32 min.

\section{Quantificação de peptídeos e aminoácidos} livres nos hidrolisados de caseína

O método rápido da Área Corrigida da Fração (ACF), desenvolvido por Silvestre et al. (1994a, b), foi utilizado para quantificar os peptídeos e aminoácidos livres presentes nos hidrolisados de caseína. As amostras foram fracionadas e os valores da ACF calculados de acordo com a curva padrão estabelecida por Morato et al. (2000).

\section{Precipitação pelo ácido tricloroacético (TCA)}

O TCA foi adicionado à solução de hidrolisado, de maneira a obter uma concentração final de $10 \%$ $(\mathrm{p} / \mathrm{v})$, sob vigorosa agitação. Posteriormente, centrifugou-se a $570 \mathrm{x}$ g durante $35 \mathrm{~min}$ a $25^{\circ} \mathrm{C}$. O sobrenadante obtido foi filtrado em papel de filtro qualitativo $n^{\circ} 1$ (Whatman), e liofilizado.

\section{Emprego da Ultrafiltração}

Inicialmente, preparou-se uma solução aquosa do hidrolisado $(0,75 \mathrm{~g} / 100 \mathrm{~mL})$, que foi transferida para um tubo do sistema de ultrafiltração, previamente lavado com água, para retirada da glicerina lubrificante e outras impurezas. Centrifugou-se, em seguida, a $160 \mathrm{x} \mathrm{g}$, por $30 \mathrm{~min}$. Transferiu-se, posteriormente, o ultrafiltrado (líquido da parte inferior do tubo) para o concentrador de amostras, por um tempo suficiente para se obter a completa evaporação à temperatura de $45^{\circ} \mathrm{C}$. O resíduo foi recuperado na fase móvel (solução de ácido fórmico $0,05 \mathrm{molesL}^{-1}$, para posterior fracionamento e quantificação por CLAE-EM.

\section{Análise Estatística}

Todas as determinações foram realizadas em triplicata. Para a determinação das diferenças entre as médias, do conteúdo de aminoácidos das frações cromatográficas dos hidrolisados de caseína, foram feitos a Análise Fatorial e o Teste de Duncan (Gomes, 1990).

\section{RESULTADOS E DISCUSSÃO}

\section{Caracterização dos hidrolisados de caseí-} na

- Fracionamento por cromatografia líquida de alta eficiência - exclusão molecular: o perfil cromatográfico do hidrolisado $\mathrm{H} 1$ a $230 \mathrm{~nm}$ está apresentado na Figura 1.

Conforme descrito anteriormente (Silvestre et al., 1994a; Morato et al., 2000; Carreira et al., 2001), os hidrolisados protéicos foram separados em quatro frações por meio da CLAE-EM. A fração 1 corresponde aos grandes peptídeos contendo mais que 7 resíduos de aminoácidos; a fração 2, de 4 a 7 resíduos (médios peptídeos); a fração 3, de 2 a 3 resíduos e a fração 4 contém os aminoácidos livres. Os últimos dois picos na fração F4 correspondem à tirosina (pico Y) e ao triptofano (pico W).

- Distribuição de tirosina e triptofano nas frações cromatográficas: para se ter uma idéia mais precisa do valor nutricional dos hidrolisados protéicos, avaliou-se a distribuição de tirosina e triptofano nas diferentes frações cromatográficas (Tabela 2), especialmente na fração $\mathrm{F} 3$, visto que di- e tripeptídeos representam a forma mais facilmente assimilável desses dois aminoácidos. Além disso, considerandose a baixa solubilidade da tirosina livre, seria interessante a sua substituição em preparações dietéticas por di- e tripeptídeos contendo altos teores de tirosina solúvel (Furst et al., 1990).

A distribuição foi estimada baseando-se nas áreas relativas dos dois resíduos a $230 \mathrm{~nm}$. Observa-se na tabela 2 que a amostra original do hidrolisado H2 (tripsina $3 \mathrm{~h}+$ pepsina $2 \mathrm{~h}$ ) foi a mais vantajosa, apresentando os maiores teores de Tyr e Trp na forma de di- e tripeptídeos. Portanto, os tratamentos empregados, seja por precipitação pelo TCA ou por ultrafiltração, não contribuíram para melhorar a distribuição desses aminoácidos nas frações cromatográficas.

Ciênc. agrotec., Lavras. V.27, n.2, p.414-421, mar./abr., 2003 


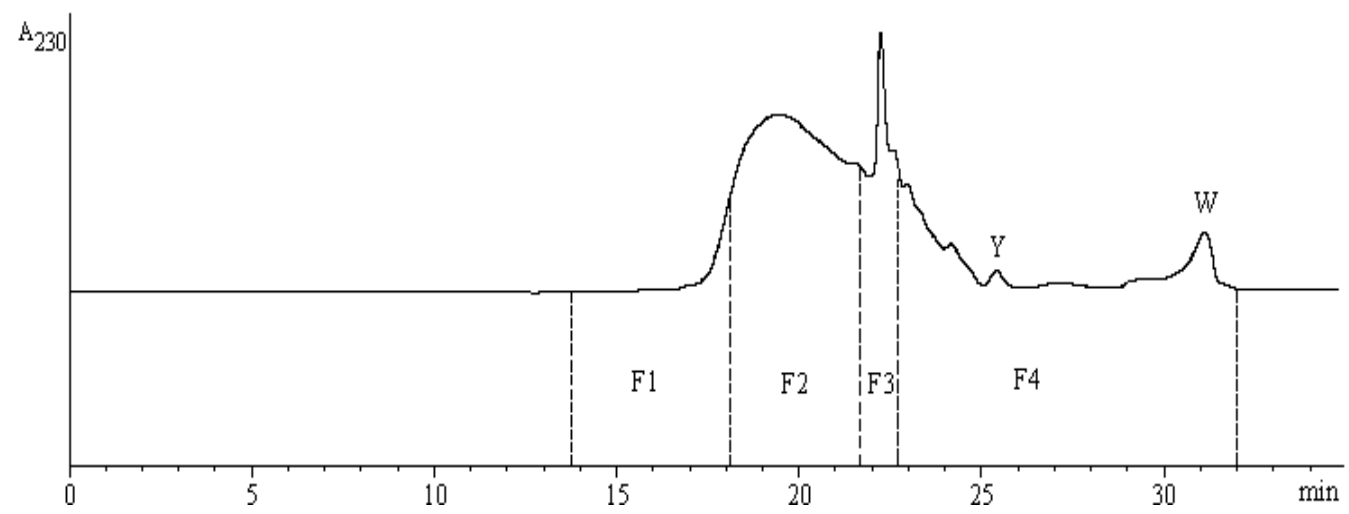

FIGURA 1 - Perfil cromatográfico do hidrolisado H1a $230 \mathrm{~nm}$. F1: grandes peptídeos (> 7 resíduos de aminoácidos); F2: médios peptídeos (4 a 7 resíduos de aminoácidos); F3: di- e tripeptídeos; F4: aminoácidos livres. Y = tirosina; $\mathrm{W}=$ triptofano.

TABELA 2 - Teores de tirosina (Tyr) e triptofano (Trp) presentes nas frações cromatográficas dos hidrolisados de caseína, a $230 \mathrm{~nm}$.

\begin{tabular}{ccrccc}
\hline \multirow{2}{*}{ Hidrolisados } & \multirow{2}{*}{ Aminoácidos } & \multicolumn{4}{c}{ Frações cromatográficas (\% área total) } \\
\cline { 2 - 6 } & & F1 & F2 & F3 & F4 \\
\hline \multirow{2}{*}{ H1 } & Tyr & 29,01 & 12,42 & 0,27 & 51,7 \\
& Trp & 5,31 & 16,03 & 53,63 & 10,49 \\
\hline \multirow{2}{*}{ H1T } & Tyr & 22,34 & 19,36 & 36,56 & 21,75 \\
& Trp & 18,11 & 29,58 & 13,49 & 39,62 \\
\hline H1U & Tyr & 14,57 & 24,19 & 35,85 & 25,39 \\
& Trp & 26,21 & 30,20 & 12,79 & 30,79 \\
\hline H2 & Tyr & 9,54 & 0,89 & 65,17 & 24,39 \\
& Trp & 11,22 & 5,18 & 59,24 & 24,36 \\
\hline H2T & Tyr & 8,34 & 18,12 & 45,22 & 28,32 \\
& Trp & 22,21 & 17,65 & 24,61 & 35,53 \\
\hline H2U & Tyr & 24,90 & 20,95 & 36,00 & 18,14 \\
& Trp & 27,69 & 22,42 & 25,12 & 24,76 \\
\hline H3 & Tyr & 16,50 & 19,27 & 33,07 & 31,16 \\
& Trp & 5,36 & 29,00 & 5,12 & 60,52 \\
\hline H3T & Tyr & 24,02 & 34,45 & 28,80 & 17,13 \\
& Trp & 13,93 & 7,47 & 44,78 & 33,82 \\
\hline H3U & Tyr & 24,30 & 14,70 & 29,10 & 31,92 \\
& Trp & 18,25 & 17,20 & 16,89 & 47,68 \\
\hline
\end{tabular}

H1, H2 e H3: hidrolisados originais; H1T, H2T e H3T: após a precipitação com TCA; H1U, H2U e H3U: após a ultrafiltração. F1: grandes peptídeos (> 7 resíduos de aminoácidos); F2: médios peptídeos (4 a 7 resíduos de aminoácidos); F3: di- e tripeptídeos ; F4: aminoácidos livres. 


\section{Precipitação pelo ácido tricloroacético (TCA)}

O efeito da precipitação pelo TCA sobre o perfil peptídico dos hidrolisados de caseína pode ser visto na Tabela 3.

Pode-se observar que esse tratamento foi prejudicial para o valor nutritivo de todos os três hidrolisados estudados, tendo reduzido os teores de di- e tripeptídeos. No caso de $\mathrm{H} 1$ e de H3, houve, ainda, uma elevação da quantidade de grandes peptídeos e de aminoácidos livres, respectivamente.

O TCA pode ser usado como agente precipitante de proteínas e de peptídeos provenientes da hidrólise enzimática, e a sua eficiência em precipitar grandes peptídeos foi relatada por Greenberg \& Shipe (1979), uma vez que empregando-se esse ácido na concentração de $10 \%$ para precipitar hidrolisado pepsínico parcial de albumina de ovo, encontraram-se $79 \%$ de nitrogênio solúvel, contendo de 3 a 4 resíduos de aminoácidos. Neste estudo, foi utilizada uma coluna Sephadex (G100) para fracionar e estimar o tamanho dos peptídeos, a qual, segundo alguns autores, apresenta inconvenientes, tais como, interações secundárias entre o soluto e o suporte e a ineficiência para separar pequenos peptídeos (Kopaciewicz \& Regnier, 1982; Verneuil et al., 1990; Lemieux et al., 1991; Golovchenko et al., 1992). Da mesma maneira, Addeo et al.
(1992), ao utilizar TCA a $12 \%$ em um extrato do queijo Parmigiano-Reggiano (PR), fracionado em coluna C18, obtiveram um precipitado contendo peptídeos com mais de 40 resíduos de aminoácidos $(\sim 4.100 \mathrm{Da})$, isolando no sobrenadante apenas peptídeos de baixo peso molecular. Entretanto, pelos os resultados encontrados no presente trabalho, não se confirmam essas descrições, uma vez que o TCA reduziu o teor de grandes peptídeos de apenas um dos hidrolisados analisados. Isso pode ser explicado, pelo menos em parte, pelo fato de que a precipitação de peptídeos pelo TCA não está relacionada apenas ao tamanho da cadeia, mas é também fortemente influenciada pelo grau de hidrofobicidade dos peptídeos (Yvon et al., 1989). Deve-se ressaltar, ainda, que o suporte cromatográfico empregado no presente trabalho foi extensivamente estudado anteriormente por Silvestre et al. (1994 a) e, ao contrário dos utilizados pelos autores citados acima, mostrou ser eficiente no fracionamento de peptídeos, de acordo com o tamanho da cadeia. Além disso, em nenhum dos relatos da literatura foi observado o efeito da precipitação pelo TCA sobre o teor de di- e tripeptídeos. A redução apenas na quantidade de grandes peptídeos obtida pelos outros autores não apresenta uma garantia da qualidade nutricional de hidrolisados protéicos (González-Tello et al., 1994).

TABELA 3 - Teores de peptídeos e aminoácidos livres das frações cromatográficas dos hidrolisados de caseína originais e após o emprego da ultrafiltração e da precipitação com TCA.

\begin{tabular}{|c|c|c|c|c|}
\hline \multirow[b]{2}{*}{ Hidrolisados de caseína } & \multicolumn{4}{|c|}{ Perfil cromatográfico } \\
\hline & Grandes peptídeos & Médios Peptídeos & Di- e Tripeptídeos & $\begin{array}{c}\text { Aminoácidos li- } \\
\text { vres }\end{array}$ \\
\hline $\mathrm{H} 1$ & $15^{\mathrm{a} / 1}$ & $46^{\mathrm{a} / 2}$ & $36^{a / 3}$ & $4^{\mathrm{a} / 4}$ \\
\hline $\mathrm{H} 1 \mathrm{~T}$ & $47^{\mathrm{b} / 1}$ & $33^{b / 2}$ & $9^{b / 3}$ & $4^{\mathrm{a} / 4}$ \\
\hline H1U & $32^{b / 1}$ & $29^{\mathrm{b} / 1}$ & $11^{\mathrm{b} / 2}$ & $29^{\mathrm{b} / 1}$ \\
\hline $\mathrm{H} 2$ & $42^{\mathrm{a} / 2}$ & $14^{\mathrm{a} / 2}$ & $16^{\mathrm{a} / 3}$ & $20^{\mathrm{a} / 4}$ \\
\hline $\mathrm{H} 2 \mathrm{~T}$ & $33^{b / 1}$ & $33^{b / 1}$ & $9^{b / 2}$ & $25^{\mathrm{b} / 3}$ \\
\hline $\mathrm{H} 2 \mathrm{U}$ & $18^{\mathrm{b} / 1}$ & $42^{\mathrm{b} / 2}$ & $12^{b / 3}$ & $27^{\mathrm{b} / 4}$ \\
\hline H3 & $17^{\mathrm{a} / 1}$ & $33^{\mathrm{a} / 2}$ & $33^{\mathrm{a} / 2}$ & $15^{\mathrm{a} / 1}$ \\
\hline $\mathrm{H} 3 \mathrm{~T}$ & $18^{a / 1}$ & $33^{\mathrm{a} / 2}$ & $5^{\mathrm{b} / 3}$ & $45^{\mathrm{b} / 4}$ \\
\hline $\mathrm{H} 3 \mathrm{U}$ & $13^{\mathrm{b} / 1}$ & $23^{\mathrm{b} / 2}$ & $9^{\mathrm{b} / 3}$ & $55^{\mathrm{b} / 4}$ \\
\hline
\end{tabular}

H1, H2 e H3: hidrolisados originais; H1T, H2T e H3T: após a precipitação com TCA; H1U, H2U e H3U: após a ultrafiltração. Grandes peptídeos (> 7 resíduos de aminoácidos); médios peptídeos (4 a 7 resíduos de aminoácidos); di- e tripeptídeos: 2 a 3 resíduos ; aminoácidos livres. Os resultados representam a média das triplicatas. Médias indicadas por letras iguais não diferem entre si $(p<0,05)$ na comparação de uma coluna. Médias indicadas por números iguais não diferem entre si $(p<0,05)$ na comparação de uma mesma linha. 
Considerando-se a distribuição dos dois aminoácidos aromáticos tirosina e triptofano na fração F3 (Tabela 2), o uso do TCA foi apenas benéfico para $\mathrm{H} 1 \mathrm{em}$ relação à tirosina, e para $\mathrm{H} 3$, em relação ao triptofano.

\section{Emprego da Ultrafiltração}

Este também não contribuiu favoravelmente para o perfil peptídico de todos os três hidrolisados estudados, uma vez que os teores de di- e tripeptídeos foram reduzidos, especialmente em H1 e H3 (Tabela 3). Além disto, houve um aumento na quantidade de aminoácidos livres nas três amostras analisadas, e esse mesmo efeito foi observado para os grandes peptídeos em $\mathrm{H} 1$.

Esses resultados contradizem o trabalho de vários autores que têm utilizado o processo de filtração através de membranas na recuperação de produtos de baixo peso molecular, produzindo, assim, hidrolisados protéicos de melhor valor nutricional, ricos em di- e tripeptídeos, e menor caráter antigênico (Olsen \& Nissen, 1979; Lacroix et al., 1983; Visser et al., 1992; Beresteijn et al., 1994).

Duas patentes foram encontradas na literatura, visando à preparação industrial de hidrolisados protéicos com elevado teor de di- e tripeptídeos, empregandose a ultrafiltração, seguida do fracionamento do ultrafiltrado mediante cromatografia líquida de troca de ligantes (LE-HPLC). Na primeira, Chataud et al. (1988) prepararam vários hidrolisados protéicos, empregando duas enzimas bacterianas e a tripsina, isoladamente ou em associação, e utilizaram um sistema de ultrafiltração Pleiade equipado com membranas Iris capazes de eliminar os peptídeos com massa molecular superior a 10.000 ou 15.000 Da, obtendo, assim, um ultrafiltrado de hidrolisado de caseína composto de $75 \%$ de di, tri e tetrapeptídeos, $25 \%$ de dipeptídeos e $7 \%$ de aminoácidos livres. $\mathrm{Na}$ outra, diferentes hidrolisados protéicos foram preparados empregando-se três enzimas bacterianas (Loosen et al., 1991). A ultrafiltração, através de membranas orgânicas (Polysulfone) e mineral (cerâmica) foi, também, utilizada para se eliminar peptídeos de massa molecular superior a $10.000 \mathrm{Da}$, originando um hidrolisado contendo $75 \%$ de di- e tripeptídeos, $20 \%$ de peptídeos com mais de 3 resíduos de aminoácidos e 5\% de aminoácidos livres.

A ausência de concordância dos resultados obtidos no presente trabalho com os de outros autores justifica-se, pelo menos em parte, pela diferença dos sistemas de ultrafiltração empregados e pelo suporte cromatográfico utilizado para o fracionamento dos ultrafiltrados. Apenas Aristoy \& Toldrá (1991) usaram um siste- ma de ultrafiltração semelhante, mas, com um corte de 10.000Da, e sob uma maior rotação da centrífuga.

Em relação à distribuição de tirosina e triptofano na fração F3 (Tabela 2), o uso da ultrafiltração foi vantajoso apenas para $\mathrm{H} 1$, em relação à tirosina, e para H3, em relação ao triptofano.

\section{Comparação entre a precipitação pelo TCA e a Ultrafiltração}

A comparação dos resultados obtidos com os dois tratamentos mostra uma ligeira vantagem da ultrafiltração sobre a precipitação com o TCA, para os hidrolisados $\mathrm{H} 2$ e H3, especialmente com relação aos teores de grandes peptídeos, que foram reduzidos, ao invés de aumentados (H2) ou sofreram um decréscimo mais acentuado (H3). Para H1, entretanto, o emprego do TCA superou, mesmo que seja por pouco, o da ultrafiltração, já que não alterou a quantidade de aminoácidos livres.

Levando-se em conta que esses dois tratamentos têm sido utilizados por outros autores, como citado anteriormente, para reduzir os teores de grandes peptídeos, a ultrafiltração mostrou ser o método de escolha. Entretanto, os dois procedimentos utilizados no presente trabalho também provocaram uma redução de di- e tripeptídeos, o que é indesejável do ponto de vista nutricional.

Deve-se ressaltar que, em nenhum outro estudo relatado na literatura, o efeito desses dois tratamentos sobre o perfil peptídico de hidrolisados protéicos foi abordado com a profundidade considerada no presente trabalho.

\section{CONCLUSÃO}

A precipitação pelo TCA e o emprego da ultrafiltração, nas condições aqui utilizadas, alteraram o perfil peptídico dos hidrolisados de caseína, tendo reduzido os teores de di- e tripeptídeos, na maioria das amostras analisadas. Esses resultados contradizem outros relatos da literatura, mas poderiam ser explicados, pelo menos em parte, pelo emprego de um sistema e/ou condição de ultrafiltração diferente dos utilizados por outros autores, como também de um suporte cromatográfico eficiente no fracionamento de peptídeos, de acordo com o tamanho molecular, ao contrário dos anteriormente descritos. No caso do TCA, acrescenta-se que a hidrofobicidade das moléculas interfere nesse procedimento, levando à precipitação de peptídeos com cadeias de tamanho variado.

\section{AGRADECIMENTOS}

À FAPEMIG a ao CNPq pelo apoio financeiro. 


\section{REFERÊNCIAS BIBLIOGRÁFICAS}

ADDEO, F.; CHIANESE, L.; SALZANO, A; SACCHI, R.; CAPPUCCIO, U.; FERRANTI, P.; MALORNI, A. Characterization of the $12 \%$ trichloroacetic acidinsoluble oligopeptides of parmigiano-reggiano cheese. Journal of Dairy Research, New York, v. 59, n. 3, p. 401-411, 1992.

ANANTHARAMAN, K.; FINOT, P. A. Nutritional aspects of food proteins in relation to technology. Food Review International, New York, v. 9, p. 629-655, 1993.

ARISTOY, M.; TOLDRÁ, F. Desproteinization techniques for HPLC amino acids analysis in fresh pork muscle and dry-cured ham. Journal of Agricultural and Food Chemistry, Washington, v. 39, n. 10, p. 1792-1795, 1991.

BERESTEIJN, E. C. H. V.; PEETERS, R. A.; KAPER, J.; MEIJER, R. J. G. M.; ROBBEN, A. J. P. M.; SCHMIDT, D. G. Molecular mass distribution, immunological properties and nutritive value of whey protein hydrolysates. Journal of Food Protection, Ames, v. 57, n. 7, p. 619-625, 1994.

CARREIRA, R. L.; MORAIS, H. A.; BARBOSA, C. M. S.; MOTTA, S.; SILVESTRES, M. P. C. Otimização da hidrólise da caseína para elevar o teor de pequenos peptídeos: associação da pepsina, tripsina e subtilisina. Brazilian Journal of Food Technology, Campinas, v. 4, n. 65, p. 103-108, 2001.

CHATAUD, J.; DESREUMEUX, S.; CARTWRIGHT, T. Procédé de fabrication d'un hydrolysat enzymatique de protéines riche en di-et tri-peptides, utilisable notamment en nutrition artificielle et en dietétique. Neuilly-sur-Seine: Laboratório Roger Bellon, 1988.

CHERYAN, M. Ultrafiltration and microfiltration handbook. Lancaster: Technomic Publishing, 1998. 527 p.

CHERYAN, M; MEHAIA, M. A. Membrane bioreactors: enzime process. In: Biotechnology and Food Process Engineering. [S.1.: s.n.], 1990.

DEESLIE, W. D.; CHERYAN, M. Functional properties of soy protein hydrolysates from a continuous ultrafiltration reactor. Journal of Agricultural and Food Chemistry, Washington, v. 36, p. 26-31, 1988.
FURST, P.; ALBERS, S.; STEHLE, P. Dipeptides in clinical nutrition. Process of Nutritional. Society, New York, v. 49, n. 3, p. 343-359, 1990.

GOLOVCHENKO, N.; KATAEVA, I. A.; AKIMENKO, V. K. Analysis of $\mathrm{pH}$-dependent protein interactions with gel filtration medium. Journal of Chromatography, Amsterdam, v. 591, n. 1, p. 121128, 1992.

GOMES, F. P. Curso de estatística experimental. 13. ed. Piracicaba: Nobel, 1990. 467 p.

GONZÁLEZ-TELLO, P.; CAMACHO, F.; JURADO, E.; PAÉZ, M. P.; GUADIX, E. M. Enzymatic hydrolysis of whey proteins. II. Molecular-weight range, Biotechnology and Bioengineering, New York, v. 44, n. 4, p. 529-32, 1994.

GREENBERG, N. A.; SHIPE, W. F. Comparison of the abilities of trichloroacetic, picric, sulfosalicylic, and tungstic acids to precipitate protein hydrolysates and proteins. Journal of Food Science, Chicago, v. 44, n. 6, p. $735-737,1979$.

GRIMBLE, G. K.; KEOHANE, P. P.; HIGGINS, B. E.; KAMINSKI JUNIOR, M. V.; SILK, D. B. A. Effect of peptide chain length on amino acid and nitrogen absorption from two lactoalbumin hydrolysates in the normal human jejunum. Clinical Science, London, v. 71, n. 1, p. 65-69, 1986.

HARA, H.; FUNABIKI, R.; IWATA, M.; YAMAZAKI, K. Portal absorption of small peptides in rats under unrestrained conditions. Journal of Nutrition, Bethesda, v. 114, n. 3, p. 1122-1129, 1984.

KEOHANE, P. P.; GRIMBLE, G. K.; BROWN, B.; SPILLER, R. C. Influence of protein composition and hydrolysis method on intestinal absorption of protein in man. Gut, London, v. 26, n. 4, p. 907-913, 1985.

KOPACIEWICZ, W.; REGNIER, F. E. Nonideal sizeexclusion chromatography of proteins: effects of $\mathrm{pH}$ at low ionic strength. Analytical Biochemistry, San Diego, v. 126, n. 4, p. 8-16, 1982.

LACROIX, M.; AMIOT, J.; BRISSON, G. J. Hydrolysis and ultrafiltration treatment to improve the nutritive value of rapeseed proteins. Journal of Food Science, Chicago, v. 48, n. 6, p. 1644-1645, 1983.

Ciênc. agrotec., Lavras. V.27, n.2, p.414-421, mar./abr., 2003 
LEMIEUX, L.; PIOT, J. M.; GUILLOCHON, D.; AMIOT, J. Study of the efficiency of a mobile phase used in size-exclusion HPLC for the separation of peptides from a casein hydrolysate according to their hydrodynamic volume. Journal of Chromatography, Amsterdam, v. 32, n. 3, p. 499-504, 1991.

LOOSEN, P. C., BRESSPOLLIER, P. R., JULIEEN, A. R., PEJOAN, C. H., VERNEUIL, B. Procede pour preparer um hydrolysat enzymatique. Tessenderlo Cheemie n. v. [BE/BE]; Stationsstraat, B-3980 Tessenderlo (BE). A23J3/34, C12P21/06 C12S3/14, C07K15/00//A61K37/18, A23J3/04, 3/14. FRPCT/BE91/00001， W091/10369. 11/01/1991; 25/07/1991.

MORATO, A. F.; CARREIRA, R. L.; JUNQUEIRA, R. G.; SILVESTRE, M. P. C. Optimization of casein hydrolysis for obtaining high contentes of small peptides: use of subtilisin and trypsin. Journal of Food Composition and Analysis, Roma, v. 13, n. 3, p. 101-117, 2000 .

OLSEN, H. S.; NISSEN, J. A. Industrial production and applications of a soluble hydrolysated soya protein. Process Biochemistry, London, v. 14, n. 6, 1979.

SILVESTRE, M. P. C.; HAMON, M.; YVON, M. Analyses of protein hydrolysates. 1. Use of poly (2- hydroxyethyl-aspartamide)-silica column in size-exclusion chromatography for the fracionation of casein hydrolysates. Journal of Agricultural and Food Chemistry, Washington, v. 42, n. 12, p. 2778-2782, 1994a.

SILVESTRE, M. P. C.; HAMON, M.; YVON, M. Analyses of protein hydrolysates. 2. Characterization of casein hydrolysates by a rapid peptide quantification method. Journal of Agricultural and Food Chemistry, Washington, v. 42, n. 12, p. 2783-2789, 1994b.

VERNEUIL, B.; BRESSOLIER, P. H.; JULIEN, R. Quantification of amino acids, and di- and tripeptides in nutritional interest protein hydrolysates by ligand exchange chromatography in combination with Edman degradation. In: SYMPOIUM ON PURIFICATION TECHNOLOGIES, 4., 1990. Proceedings... [S.1.: s.n.], 1990. p. $253-258$.

VISSER, S.; SLAGEN, C. J.; ROBBEN, A. J. P. M. Determination of molecular mass distributions of whey ptotein hydrolysates by high-performance sizeexclusion chromatography. Journal of Chromatography, Amsterdam, v. 599, n. 2, p. 205-209, 1992.

YVON, M.; CHABANET C.; PÉLISSIER, J. P. Solubility of peptides in trichloroacetic acid (TCA) solutions. International Journal of Peptide and Protein Research, Haguenau, v. 34, n. 1, p. 166-176, 1989. 